\title{
IDENTITY TRANSFORMATION OF JOSEPHINE ALIBRANDI AND JOHN BARTON IN THE NOVEL LOOKING FOR ALIBRANDI (BY MELINA MARCHETTA)
}

\author{
Ferdi
}

\begin{abstract}
This paper examines the progress of identity transformation of Josephine Alibrandi and John Barton in the novel Looking for Alibrandi. Josephine and John come from different family backgrounds. Josephine comes from an Italian immigrant family who lives in suburban area, while, John Barton comes from a politician family in Australia. Although they come from different family backgrounds, they still have the same problems in their identities. Their desire to be seen as themselves in the society makes them intend to find their identity. The reason I intend to do a research in this novel because I think this novel is interesting for teenagers and it can inspire them to find their identity in the society. Identity transformation is something that should and will occur in anyone's life. Josephine Alibrandi and John Barton represent the general group of teenagers in the world in terms of gender and social class. Each individual, however, have their own solution and way to find their identity. This paper concludes that identity transformation happens in both Josephine Alibrandi and John Barton in different ways. Each of them also has different strategies to overcome the problem and they also get different results.
\end{abstract}

Keywords

transformation of identity, social class, teenager

\section{INTRODUCTION}

The main objective of this essay is to analyze the transformation of identity of the two main characters in Looking for Alibrandi novel transform since they come from different family backgrounds. The reason why I choose this topic in this paper because I like the novel, also I have not found any paper which discussed about the transformation of identity in this novel. Looking at the novel's target reader which more focused on the teenager and the problem of finding their identity, it interested me to talk about the identity transform of the novel. Then, I will analyze the reason why they want to change their identity. In this essay, I would like to bring up the issue of discrimination against immigrants, especially Italian immigrants, in Australia. Then, I will make a connection between discrimination and the process of identity transformation on Josephine Alibrandi. On the other hand, John Barton who came from a family with good-reputation 
also has a problem in finding his true identity. John Barton is trapped in a family dominated by politicians. The pressure given to him makes him try to be a politician, but at the end he does something else to find his real identity. These two factors will lead to the transformation of identity on both JosephineAlibrandi and John Barton. They have different backgrounds, different strategies to overcome their problem, and different outcomes. These issues will be used to analyze the process of transformation identity of both main characters.

In order to do my research, the first thing that I am going to do is read the novel in order to understand the story. It will help me to find some points that I am going to expand in this paper. Then, I will start to read critically. In this critical reading, I will find some implied meaning in this novel. After that, I will bring up some issues which are related with the topic. For instance, I will discuss the issue of discrimination of immigrants in Australia, and feminist issues. Next, I will talk about the identity of the two main characters in this novel. After that, I will talk about the process of transformation of identity of both characters by using some perspectives that I will explain before as supporting details. Finally, I will talk about the outcome for each of them. I will explain the background of both characters, the process of their identity transformation and the outcome that they get.

Looking for Alibrandiis the first novel by Melina Marchetta, an Australian author. This novel mainly talks about the life of a smart Italian immigrant teen who life in Australia. Josephine Alibrandi's mother is a single parent. She gets pregnant by the boy next door when she was 17 . Unlucky for her that the boy's family move to another city without knowing that their son is impregnate the girl next door. Then Josephine's mother chooses to born her instead of doing an abortion and that's the way Josephine born. Josephine grows as a clever student and she get scholarship in a top private catholic school in Australia. In this school, Josephine meets her number one enemy 'Poison Ivy" who always insult Josephine with racist word. Then, Josephine meet two boys who are really different each other, John Barton and Jacob Coote, who are in this novel will have a close relationship with Josephine. This novel explains about the problem in Josephine's family since each member of Josephine's family has their own problem. This novel has get award for Children's book of the year (1993) and "Books I Love Best Yearly award (1995, and 2000). In 2000, as a result of the success this novel gain, the novel was adapted into a film.

\section{PREVIOUS RESEARCH}

Nowadays, the issue of identity transformation is not new in this world. The process of changing identity of one person mostly happens to people in middle and lower class. However, it is not limited to middle and lower class family only. Identity transformation occurs normally when someone feels unsatisfied with their identity and they want to get a 
new identity they desire. The research by Becker 1963, et all in Tammy L.Anderson (1993) states that "Interactionists have traditionally maintained that identity transformation is an important outcome of exiting deviant careers". Another research in transformation identity is a research by Goffman (1961; 1963), Glasser and Straus (1971), and Hughes (1971) in Tammy L. Anderson. Goffman and some researchers above view identity transformation as an outcome of career movement and/or status passage. Both of the previous researches above have a similarity which sees identity transformation as an outcome of something. Since these statements are similar with my topic, my research will use these two previous researches in order to find the identity transformation in my corpus.

The previous research by Erik Erikson in Deborah L. Wise's work "Identity Theory: A Literature Review" has shown there are eight stages of Psychosocial development and one of them is Adolescence (Age 12-18). Erikson's research states that in this phase people will confront identity and identity confusion. This research has a connection with my corpus which will focus on adolescence. Looking for Alibrandi is not so famous, but the issues which are brought by this novel are so valuable. The issue of feminist, multiculturalism, and identity are three main issues in this novel. Although this novel win some awards, it is not easy to find any previous research on this novel. In Journal of Adolescent $\mathcal{E}$ Adult Literacy by Barbara Comber and Helen Nixon, they talk about the review of Looking for Alibrandiand they analyze the central character of this novel, Josephine Alibrandi, who represents the three generation of Italian-Australian immigrant (her grandmother, her mother, and herself). This analysis also has a connection to my corpus because one character I am going to explain more is the character of Josephine Alibrandi. In this paper, I will combine the previous researches of identity transformation to the corpus I have to produce an analysis of identity transformation in Looking for Alibrandi novel. It will be different with previous research by Barbara Comber and Helen Nixon because in this paper I will focus more on transformation identity of Josephine Alibrandi and John Barton who haven't been explain in their paper.

\section{THEORY AND METHOD}

There are some theories that I am going to use in order to support my research. The first theory is a theory by Erik Erikson. Based on Erik Erikson'sPersonality Theories in Dr. C, George Boeree, there are eight stages of identity development. One of many stages that Erikson's explain in his theory is the adolescent stage (12-18 years old). Erikson tells that this stage is the stage of "identity versus Role confusion". This stage is the stage when adolescents try to find their identity on their own. They have to struggle to find their own identity while interacting with social environment. The theory by Erik Erikson has a similarity with my corpus. The corpus, Looking for Alibrandi, is a teenage novel, and the characters I am going to explain in this novel are two adolescents who search for their identity. Josephine feels that she cannot interact well with her friends in school 
because of her identity as an immigrant. Actually, Josephine 'Josie' Alibrandi is a very clever student since she gets a scholarship for a famous catholic school in Australia, but that does not matter, and the majority of students in her school do notpay any attention to Josephine. On the other hand, John Barton, a charming guy from a famous politician family, is also a teenage kid who is not satisfied with his identity as a son of a famous politician. John Barton's family expects him to be a politician like his father and grandfather. The second theory is a theory by Bekcer(1963) in Tammy L. Anderson, who considersidentity transformation as an important part of someone's life. He statesthat "Interactionists have traditionally maintained that identity is an important outcome of exiting deviant careers". This theory tells that identity is one important aspect for one people to change their careers. For example, If there is a preman ${ }^{1}$ who wants to stop an activity as a preman (insaf), he has to change his identity first. The process of identity change can be done by changing the attitude of the preman itself. This theory can be connected to my corpus since I will explain about John Barton who wants to change his careers. In this novel, John Barton does not want to be a politician just like his fathers, grandfather and great grandfather did. He wants to do another job and he also wants to get recognized by the society for his works, not by what his ancestors had done. In order to get the recognition as "John Barton", he has to change his identity from "Barton's family member" into "John Barton". John Barton has been expected by his family, especially his father, to be a politician, but he is not interested in becoming a politician. Another theory is a theory by Goffman $(1961,1963)$. Heviewsidentity transformation as an outcome of career movement and/or status passage. This theory has a similarity with the first theory by Erik Erikson. This theory views identity transformation as an important role in changing career movement and or someone's status/identity.

In this research, I will explain the identity transformation of the two main characters whocome from two different social classes. I intend to highlight that the identity transformation is not something which can only happen to middle or low social class family, but it also can be happen to people from high social class family. I use the two main characters in this novel, one is a girl who comes from an Italian-immigrant family and the other is a boy coming from a famous politician family. My hypothesis is the process of identity transformation of these two different characteristics related to their social backgrounds, which leads to different strategies and different outcomes in their search for identity.

I will begin my research by reading the novel by Melina Marchetta, Looking for

\footnotetext{
${ }^{1}$ The word preman comes from Free Man which means a person who lives his or her life on their own. Their ideology in living the ideal life is to live without paying attention to other people's opinion. In Indonesia, preman usually have negative meaning, similar to thug or street punk.

${ }^{2}$ Insaf is the act of stopping committing sinful action.
} 
Alibrandi. In this research, I will use literary study and collect the data from the novel. In addition to increase my knowledge about immigrant issues in Australia, I will also search information from the internet about the issue Melina Marchettaraisesin her novel. In order to do a research about this novel, I will read the novel at least four times. First, I will read this novel to find out the general story of this novel. At this time, I will only focus on understanding the story of the novel in general. At the second time, I will do a close reading. I will focus on the issue that will support my research, such as multiculturalism, and feminism. Third, I will focus onanalyzingthe character of Josephine Alibrandi. I will analyze the identity of Josephine, and then the process of her identity transformation. Finally, I will read this novel again by focusing on John Barton's character. I will analyze hisidentity, and the process of identity transformation taking place in him. After reading the novel, I will find some journals and information about immigrants' lives in Australia, especially Italians. Others examples and data from other sources will give me more understandingof discrimination againstimmigrants in Australia.

Looking for Alibrandiis the first novel by Melina Marchetta, an Australian writer, who has been adapted into a film in 2001. This novel tells us the story of a girl from an Italian immigrant family who lives in Australia. As a result, the girl is only seen as an immigrant from a lower social-class family. There are some issues which Melina Marchettaraisesin this novel, such as multiculturalism, feminism, and identity. Multiculturalism ${ }^{3}$ issues can be seen from some Italian cultures which arewell-preserved in Italian immigrant environment. Feminism issue can be seen from both Josephine Alibradi and her mom, Christina Alibrandi, who is a single parent. As a single parent, Christina Alibrandidoesnotwant to be seen as a fragile woman and shows that she can do everything, although she is only a single parent. Finally, the identity issue in this novel can be seen from both Josephine Alibrandi and John Barton, who are not satisfied with their status and want to find some otheridentity that will comfort them both. The issue of identity is the main issue I will examinein this paper. Both multiculturalism issue will be used as aframework of analysis.

\section{Identity}

The meaning of "identity" in Oxford Monolingual Dictionary is the characteristics, feelings, or beliefs that distinguish people from others. Everyone is unique because each person has their own characteristics, feelings, or beliefs. Even twin brother or twin sister have their own characteristics and feelings, so people can distinguish them. Identity is not an exclusive thing because everybody definitely has their identity whether they

\footnotetext{
${ }^{3}$ Multiculturalism is a body of thought in political philosophy about the proper way to respond to cultural and religious diversity. (Song, Sarah (2010). Multiculturalism. Retrieve November 26, 2012, from http:// plato.stanford.edu/archives/win2010/entries/multiculturalism).
} 
come from rich or poor family. People start to have an identity since they were born until the end of their life. Identity can be categorized into biological and social identities. Biological identity is an identity which everybody gets since they were born and it will be difficult to change this kind of identity. The example of biological identity is an identity as a boy, or girl. It will be difficult to transform the identity of one person from a boy into a girl and the other way around. Although the transformation of this kind of identity is not an impossible thing to do, it will be difficult to be accepted by the society. Others example of biological identity is race, ethnic group, and another identity that people will get automatically when they are born.

People's identity is not limited only by biological traits. People also have social identity. People grow every day and as the time passes, they will get new identities. The more people do social interaction, the more identities they will get. Social identity is an identity that people get in their social life as a result of social interaction with others. The example of social identity is a job, such as driver, teacher, and any other job. Job provides people to have a new identity because job is not something that everybody can do by themselves. Social identity is different with biological identity. Normally, people will acquire their social identity when they become an adult. When someone transform into an adult, people start to recognize their position in the society, so they will get their identity in the society. Social identity is easier to be transformed from one identity into another identity, compare to biological identity. For example, people can easily change their job without any serious problem with society. Both biological and social identities are not only being used to distinguish one person to another, but it alsocan be used to find the similarity of group of people. For example, the identity as a boy is not only being used to distinguish the boy with a girl, but also make the boy realize that they have the similarity with another group of boys.

Based on the Oxford Monolingual Dictionary, the meaning of "transformation" is a complete change in somebody/something. The combination of "transformation" and "identity" will synthesize the definition of identity transformation as a complete change in somebody's characteristics, feelings, or beliefs that distinguish people from others. Identity transformation is not a spontaneous action which occurs anytime and anywhere, without any reason. There will always be a reason or two, why identity transformation occurs. Based on Lacan statement in MadanSarup (2003), an individual and society cannot be separated. The statement states that an individual and society cannot be separated because an individual is part of society. As a part of society, an individual must be influenced by the society itself and the other way around. When we are on our way to understand an individual, it will be possible to analyze the social environment first. For example, if we intend to find out more about an individual who works as a thief, it will be possible if we analyze his/her social environment first. Then, we will possibly get the reason why this individual works as a thief. Probably that individual 
live in the environment that dominated by thieves and they influences the individual to be one of them.

\section{ANALYSIS}

\section{Analysis on Josephine Alibrandi}

Josephine Alibrandi is a smart teenage girl from Italian immigrant family who moves to Australia in order to get a better life. Josephine Alibrandi is a clever student in her school since she gets a six years' scholarship in St. Martha, a top private school in Sydney. Cleverness is not the only positive things that Josephine has because she is also an ambitious girl. It can be seen from her position in school as a vice captain in St. Martha. As a top private school in Sydney, St. Martha is dominated by Australians and some immigrants who have money to educate their children in that school. School captain and vice-captain are being selected by the students of the school itself, so it means that Josephine, who comes from poor and immigrants family, can compete with other Australian although she is not considered as an Australian in her school. At that time, immigrants are being seen as a second class society and it's not easy to get recognition by the society unless you have much money. Then, in order to change the stereotype of immigrant, especially Italian immigrant in Australia, Josie becomes the vice-captain in her school, St. Martha. The starting point of Josephine Alibrandi's story happens when Josephine's grandmother and grandfather move from Italia to Australia in order to get a better life. Life as an immigrants are not as easy as today. Nowadays people do not really care if they are immigrants or not and people still recognize the immigrants as the member of society. In the novel, Melina Marchetta tells the reader that Australians are not giving the immigrants, especially for poor immigrants, any recognition. As an immigrant, Josephine grandmother and grandfather are not recognized by the Australian. It can be seen from the place where Josephine's grandfather and grandmother live. Josie's grandparents live in suburban area for two reasons. The first reason is they are poor, and the second one is they do not like to join the society, since they are not being seen as members of Australian society. The second generation of this Italian immigrant is Josephine Alibrandi's mother, Christina Alibrandi. Christina Alibrandi is still being seen as an immigrant's child and it means an immigrant, although she was born in Australia. Christina's problem is not only immigrant problem, but also another everyday life problem because she is anunmarried woman who has a child. At Christina's time, single mother, especially for an unmarried mother, is still a taboo whether in Australia and Italian culture. The next generation is Josephine Alibrandi's generation. In this generation, the attitude toward the immigrant has not changed. Immigrant is still being considered as a second class society. Josephine grows as a clever student and she get scholarship in a top private catholic school in Sydney. It does not change the reality that she comes from Italian immigrant family. As a result, she cannot get many friends in the 
school. Based on the statement from Lacan in MadanSarup in the previous paragraph which state that an individual cannot be separated from the society, it also can be used in this part. In Josephine Alibrandi's time, Josie who gets the scholarship in a top private catholic school in Australia spent much of her time in this school which is dominated by Australian. The fact that Josie is being discriminated by her school friends make Josie gives their best to get recognition by her school friends.

\section{Analysis on John Barton}

John Barton is a charming boy from a top private school in Australia. Barton family is a member of a famous politician family. Barton's family political career starts since John Barton's great grandfather who was a backer of first Liberal prime minister. It starts from his great grandfather who is a member of party in Australia. Then his grandfather and her father are also politicians. Facing the fact that he lives in a famous politician family, John Barton has no choice to do another job except to be a politician. His Fathers expect him to be a politician just like what he did, his grandfather did, and his great grandfather did. In his school, he is not being seen as himself. He is being seen as a member of famous politician family in Australia. In the novel, John Barton once told Josie "They knew I was going to be school captain in Year 7 because every other Barton had been one". The statement of John Barton proves that he want to be recognize as a "John Barton", not as the other Barton. John Barton seems unsatisfied with his identity as a "Barton" and he wants to change his identity into a new identity that everybody will see him as "John Barton" or just "John". John Barton does not what he want to do, but become a politician is out of choice. After talking with Josephine in private, John reveals his desirability to not become a politician just like what his father and his family expects.

\section{The Explanation of Identity Transformation}

Transformation, based on Oxford Monolingual Dictionary, is a complete change in somebody or something. If we combine the explanation of "transformation" and "identity" it would be a complete change in somebody's characteristics, feeling, or beliefs that distinguish people from others. The process of identity transformation can be caused by many things. One of them is because people feel unsatisfied with the previous identity they got and want to get a new one.Identity transformation usually happens when people in teenage stage (between 12-18 years old). Teenage is a crucial stage in someone's life because it's a transition stage when a person wants to change their identity as a child into an adult. Erik Erikson's personality theories in Dr. George Boeree states that there are eight stages of identity development in someone life. One of many stages is the adolescent stage (12-18 years old). The adolescent stage (12-18 years old) is the stage of "identity versus Role confusion". This stage is the stage when adolescents try to find their identity on their own. They have to struggle to find their own identity 
while interacting with social environment. In this novel, the character is mainly focused on adolescent. Josephine Alibrandi and John Barton, for example, are 17 years old. Both Josephine Alibrandi and John Barton are also in progress of finding their own identity.

\section{Analysis of the Process of identity transformation in Josephine Alibrandi}

On the previous paragraph, I have explained that everybody has two kinds of identity. The first identity is biological identity which is very hard to be changed, and the other one is social identity which is easier to be transformed. In this paragraph, I will focus on social identity transformation. Josephine social identity is an Italian immigrant in Australia, a girl who does not has a father and is a clever student in St. Martha. Although Josephine was born in Australia, the Australian still see her as an Italian immigrant. Josie herself is a woman who loves her parents' country, Italy, and also her country where she was born, Australia. In this novel, Melina Marchetta depicts Josephine Alibrandi as a girl who loves Italian and Australian simultaneously. Sometimes Josephine feels that some Italian cultures arebetter than Australian cultures, and the other time, she would criticize the Italian cultures and appreciate Australian cultures.

"I mean Australian guys don't really sit around drinking tea, yet he seems comfortable sipping his tea and talking about his mother as he does drinking his beer and chanting Tottenham soccer songs ${ }^{4 \prime} .(p g .09)$

"I like being emotional. Italians are always emotional. You Australians are cold". (pg. 250)

The two examples above are the examples of Alibrandi criticizing Australian culture. At the first example, Josephine criticizing the drinking tea ceremony by Australian which not only focuses on drinking tea, but also on a place to chit-chat about their life experience. From the first example, we can also conclude that Australiansare mostly British. The second example is the scene when Alibrandi and Jacob Coote fight each other. In the second example, explanation is being made about the fact that Australians are colder than Italian. The reason why Alibrandi says that because many Australians she meets are cold to her because of her identity as an immigrant. On the other hand, Italians will be more emotional to her, because she is also an Italian.

"I suppose it's the different cultures, I mean Italians don't live with a guy unless they're rebel Italians in the first place" (pg. 151)

"Italians are so used to bitching about people that they tend to whisper a lot even when the person is one thousand miles away or even dead" (pg. 200)

The next two examples are the examples of Alibrandi criticizing Italian culture.

\footnotetext{
${ }^{4}$ Tottenham soccer songs are songs sung by Tottenham Hotspurs football club in England.
} 
At the first example, Alibrandi criticizing the Italian culture which only allows Italians to get married with another Italians. Italian's culture is not as modern as an Australian because many of Australian cultures are being seen as taboo things in Italian culture. If the Italians get married with another people, they will be considered as a rebel Italians. The second example is the example of Italian stalking about everybody they do not like even if they are far away or probably has died.

The process of identity transformation in Josephine Alibrandi happens when she is 17 years old. At the beginning of this novel, the author tells the readers about that. In her teenage, it is a crucial moment for someone to get their identity. Erik Erikson's study in people tells that adolescent, people around 12-18 years old, will face a stage called "identity versus role confusion". Adolescent stage is the stage when 12-18 years old person struggle to find their identity. Teenagers are still facing the difficulty to find their own identity and their role in society. Josephine is a 17 years old student who also wants to transform identity. In my opinion, both finding identity and identity transformation have a similar meaning. Both of them will be used to find a new identity. Finding identity does not mean people have not yet found their identity, but it means people already have their identities without realizing it.

The process of transformation identity in Josephine's life can be seen from her effort to get recognition by Australian society. The first thing is the cleverness she has. In this book, there is a part that tells Josephine's efforts in order to get the six years scholarship.

\section{"I don't know why I tried so hard to win it (the scholarship)" (pg. 07)}

In this quotation, we can see that Josephine was not born as an intelligence person. She has to give the best effort to get the scholarship. In my research, Josephine's effort in order to get the scholarship is caused by discrimination by Australian. She wants to get the scholarship in order to get recognition by Australian. Unluckily, at that time, cleverness is not the point that is important that being seen by the society. Australian will pay more attention to people who have more money.

The second effort is her ambitions. In this part, we can see from her activity in school as a vice-captain.

"Do you think they voted me school captain because they wanted me? Get real. They knew I was going to be school captain when I was in year 7 because every other Barton has been one. It's got nothing to do with popularity. The guys don't even know me" (pg. 46)

From this quotation, it can be seen that school captain and vice-captain are being chose by the students. Josephine's achievement in her school proves that she has an ability to compete with other students in her school which is dominated by rich people. It won't be easy for Josephine to get recognition by another student, but she proves that she can 
be the vice-captain of St. Martha. Unluckily for Josephine, her activeness as a vice-captain does not really change her school life because she is still being seen as an immigrant.

The third effort is Josephine's effort to get her father's affection. In the beginning of this story, I state that Josephine's mother is a single parent. In the middle of this novel, Josephine's father, Michael Andretti, will come out and be exposed in the novel until the end of this novel. Josephine seems unsatisfied with the emergence of her father. At the beginning of Josephine's father emergence, Josephine cannot accept him, especially when her father states that he does not want to get disturbed by Josephine's life.

“Okay, he (Michel Andretti) snapped back. 'A promise. You keep out of my life, I keep out of yours 'Let's shake on it' (Pg. 69-70).

This quotation is quoted from Josephine's right after Michael Andretti (Josephine's father) has a conversation with Josephine's father. From this quotation, it can be seen that, Josephine's tone towards her father is a very angry one and she does not want Michael Andretti to disturb Josephine and Josephine's mother life.At the beginning, Josephine feels that she does not need Michael Andretti in her life. On the contrary, Josephine still needs her father. At that time, Josephine's future in St. Martha is almost finish as a drop out student when Josephine hit her friends, Carly, with her science books and break Carly's nose. As a result of her action, Carly's father comes to St. Martha and he intends to bring this case to the court. Then, the desperate Josephine Alibrandi calls her father who works as a barrister ${ }^{5}$ to come to Josephine's school. In the end, the case is closed by Michael Andretti and they come along to the exit.

"I knew how it felt walking alongside one's father. It was a great feeling" $(p g, 90)$

This quotation provesthat Josephine Alibrandiactually finds the feelings that she never felt since she was born, the feeling of her father's affection and she starts to enjoy this feelings and she lets Michael Andretti join her life once more.

The result of Josephine's identity transformation can be seen from the finishing part of this novel.The first identity she transforms is the identity as a girl who does not has a father. In the finishing part of the story, Josephine can get her father affection. It can be seen from the quotation below.

"When it was over I rang my father to pick me up. He didn't ask any question" (pg. 232)

On that quotation, it can be seen that Josephine is use the word "father" instead of Michael Andretti. In this quotation, I can conclude that Josephine is no longer worries about being seen as a fatherless girl and being called as bastard. Now, she accepts the

\footnotetext{
${ }^{5}$ Barrister is a lawyer in Britain who has the right to argue cases in the higher courts of law.
} 
role of her father and she enjoys it. The second achievement she gets is her identity. In the last chapter of this novel there is a part of Josephine tells about her nationality.

"If someone comes up and asks me what nationality I am, I'll look at them and say that I'm an Australian with Italian blood flowing rapidly through my veins.

In this quotation, Josephine no longer worries about her identity whether being seen as an Italian, or Australian. She wants to be seen as an Italian and Australian as a whole. Her pride of family as an Italian and her proud to be born in Australian are being combined into her nationality as an "Australian with Italian blood"

\section{John Barton's Identity Transformation}

John Barton appeared in this book in the fourth chapter. John Barton is a goodlooking, popular, and the greater debater who ever lived. He is a son of a member of parliament. He feels unsatisfied with his identity as a son of a member of parliament and his identity as a member of politics family. John Barton wants to get recognized by the society as a "John Barton" not as the member of Barton family.

"Do you think they voted me school captain because they wanted me? Get real. They knew I was going to be school captain when I was in year 7 because every other Barton has been one. It's got nothing to do with popularity. The guys don't even know me"(pg. 46)

"I don't know what I want out of my life, but I know what I don't want. I don't want to make promises I can't keep. I don't want my children embarrassed every time I make the wrong decision and some journalist shirts all over me in the paper" (pg. 47)

In these two quotations, it can be seen that John Barton is not interested to be a politician. In the first quotation, John Barton shows his disappointment of the election of himself. John Barton is elected as a school captain in St. Anthony. The process of John being selected as a school captain is not caused by his ability to be a school captain. John states that the reason why he is being chosen as a school captain because in year 7 every Barton has been one. He is being elected as a school captain not because he is "John Barton" but the reason is just because he is Barton. In the next sentence, John adding a sentence states that "The guys don't even know me". St. Anthony is a boy's high school, but John said that "the boys didn't even know me". It means if the boys do not know him, the reason he is being chose as a school captain is because he is "Barton". The second quotation is a statement that he does not want to be a politician although he does not know yet what he wants to be. In my opinion, the reason why he does not want to be a politician is because he does not want to be "Barton". John wants to be seen as a John Barton or just John. That's why he does not want to be a politician although he can be succeeds in politics.

Starting from chapter 14, Josephine meets John Barton on her way to the Sydney 
University library. John Barton looks so depressed and he does not really attracted with Josephine just like usual.

"I didn't win the maths competition. I didn't even get in the top five percent."(pg. 133)

"When I win a debate. When I win a football game. When I get elected school captain. When I win, win, win,' he gritted. 'and when I lose he hates me. So I have to keep on winning" (pg. 133).

At the first and second question about John Barton, John Barton has already state that he does not want to be a politician just like his father wants. Josephine actually has given John Barton a suggestion to talk to his father about his problem, but from the quotation above, it can be seen that John Barton does not talk to his father. John Barton still gives his best to fulfill her father expectation. He feels so depressed when he fails to win the mathematics competition because he afraid of making his father angry and John's father will hate him. In the second quotation, it can be seen that John father does not tolerate with any fails John did. John's father wants John to win all of the competition although the competition seems unrelated with John's future in politics.

A turning point of John Barton's life is when he gets out of his boring life. John's father gives too much pressure on John to stand on the top of the others. John's father wants john to be a politician, but since John do not really interested in politics he does not interested in politics. The effort John did to resist his father's expectation is nothing because the only thing he does is just complaining without real action. Josephine is the only place for John to complain about his father's expectation. As a result of the pressure be given to John, John suicides himself.

\section{Comparison between transformation identity between Josephine Alibrandi and John Barton}

Based on the analysis of identity transformation of Josephine Alibrandi and John Barton before, it can be seen that people, no matter from what family they come, has their own problem in identity. Josephine Alibrandi and John Barton come from different social class family but they encounter the same of identity problem. John Barton, in order to encounter his identity problem does not do a real action. At first, John Barton tells Josephine that he can not be the one that his father expectshim. Josephine told John to tell his true feeling to his parents in order to solve the problem, but John does not do that. The second, starting from chapter 14, it can be seen that John does not tell his father that he can not be a politician. In this chapter, John feel so depressed that he try to get on a top of everything but he fails. In this occasion, John, one more time, tells Josephine his incapable of being on a top everything just like his father expect him. It can be seen that John does not do an effort to change his identity. Although he wants to change his identity, his action does not show that. Finally, John Barton does an effort to change his identity. Suicide himself is a solution of John Barton to change his identity. In the 
previous, everything that John Barton does is dedicated for his father; John wants his father proud on him for his achievement. The suicide proves his rebellion and despair of his father efforts.

Josephine Alibrandi, on the other hand, has done everything to change her identity. At the beginning of analysis part in this paper, Josephine's effort to get a scholarship in a top private catholic school, St. Martha, shows an effort to get recognition by the society. This thing differentiates Josephine's effort and John Barton's effort in order to get identity from society. Josephine does anything to get recognition by the society, such as study hard to get scholarship, become a vice-captain, and study hard to be a barrister. John Barton, on the other hand, does nothing to change his identity. All John has to do is complaining about his father expectation for him to be a politician. Based on Josephine's effort, at the end of the story, Josephine can get the solution of her problem. The solution is Josephine can get the solution of her identity as an "Australian with Italian blood".

\section{CONCLUSION}

My research has already analyzed the process of identity transformation of Josephine Alibrandi and John Barton in Looking for Alibrandi. My purpose on this research was to find the process of identity transformation of Josephine Alibrandi and John Barton in this novel since they both come from different social class in Australia. My intention was to find whether social background had influence on identity transformation. In order to do my research, I had closely read the book and observed the issues of feminism, multiculturalism, and identity transformation.Internet also gives me additional information of this novel and issues existed. The issue of multiculturalism in this novel was used to help me analyze the identity of both Josephine Alibrandi and John Barton.

The process of identity transformation of Josephine Alibrandi and John Barton exists in this novel. Bothof them feelunsatisfied with the identity they have and desire a new one. The process ofidentity transformation for characters that come from lower social class, for example Josephine Alibrandi, is possible in some ways. On the other hand, higher social class characters, for example John Barton, cannot get the identity he wants and, as a mean for escape, just committing suicide. Josephine Alibrandi and John Barton commit different effort in order to get a new identity they desire. Josephine Alibrandi gives her best to get recognition by society

However, there are some issues that I have not explained more on this essay. Issue regarding multiculturalism, for example, was not analyzed deeper in this essay. Multiculturalism issue is used only as additional information to analyze the identity transformation in this paper. Another issue is feminism issue. Josephine Alibrandi and her mother show that women can stand without men's help. These issues could be further studied in order to find some issues which exist in this novel. 


\section{REFERENCES}

Sarup, Madan (2003). Posstrukturalisme dan posmodernisme: Sebuah Pengantar Kritis. Yogyakarta:Penerbit Jendela.

Stets, Jan E. \& Peter J. Burke (2000). Identity Theory and Social Identity Theory. Washington: Washington State University.

Wise, Deborah L. (n.d). Running Head: A Literature Review. Denver: University of Colorado.

Deaux, Kay (2001). Encyclopaedia of Women and Gender (1 $1^{\text {st }} 2^{\text {nd }}$ ed.). New York: Academic Press.

Boeree, C. George (1997). Personality Theories: Erik Erikson. Pennsylvania: Shippensburg University. 